\title{
Excessive Daytime Sleepiness in Parkinson's Disease: Characteristics and Determinants
}

\author{
R. Poryazova D. Benninger D. Waldvogel C.L. Bassetti \\ Department of Neurology, University Hospital Zurich, Zurich, Switzerland
}

\section{Key Words}

Excessive daytime sleepiness - Sleep onset REM •

Parkinson's disease $\cdot$ Multiple sleep latency test

\begin{abstract}
Background/Aims: Excessive daytime sleepiness (EDS) is frequent in patients with Parkinson's disease (PD). Occasionally, EDS in PD exhibits narcolepsy-like features. We aimed to assess characteristics and determinants of EDS in consecutive patients with PD. Methods: Thirty consecutive patients with PD underwent a detailed clinical examination. EDS was assessed using the Epworth Sleepiness Scale (ESS) and Multiple Sleep Latency Test (MSLT). Sleep was assessed using video-polysomnography. Cerebrospinal fluid (CSF) hypocretin-1 levels were obtained in 3 patients. Results: ESS was $>10$ in 17 patients (57\%). Mean sleep latency (MSL) on MSLT was $<5$ min in 11 patients (37\%). There was a significant negative correlation between ESS and MSL. None of the 11 patients with MSL $<5$ min showed a sleep onset REM (SOREM) episode. Patients with EDS had higher dopamine agonists/levodopa equivalent doses, higher apnea/hypopnea index and exhibited wearing-off symptoms more often. Hypocretin-1 was normal in 3 patients tested. Conclusion: EDS, which can sometimes be severe, is common in PD patients even in the absence of SOREM and detectable CSF-hypocretin deficiency. In PD, EDS is a multifaceted phenomenon, the deter-
\end{abstract}

minants of which include severity of PD, wearing-off symptoms, dosage of antiparkinsonian drugs and sleep-disordered breathing.

Copyright $\odot 2010$ S. Karger AG, Basel

\section{Introduction}

Excessive daytime sleepiness (EDS) is common, although often underestimated in patients with Parkinson's disease (PD). An Epworth Sleepiness Scale score (ESS) above 10, indicating subjective EDS, has been reported in up to $50 \%$ of patients with PD [1]. Frucht et al. [2] and other authors have reported sudden sleep episodes ('sleep attacks') causing driving accidents in PD patients taking non-ergot dopamine agonists. Severe EDS, defined as mean sleep latency (MSL) on the Multiple Sleep Latency Test (MSLT) $<5 \mathrm{~min}$, has been reported in about $20 \%$ of unselected patients with PD [3,4] and in up to $50 \%$ of PD patients with EDS [5]. Data on the frequency of sleep onset REM (SOREM) have been variable. SOREM was found in $29-39 \%$ of PD patients with EDS $[5,6]$ and in up to $70 \%$ of $\mathrm{PD}$ patients with hallucinations [7]. SOREM was also observed in a case of juvenile PD [8] and in $20-28 \%$ of unselected PD patients $[4,9,10]$. Others have reported a less frequent occurrence of SOREM in $\mathrm{PD}$ and other forms of parkinsonism [11]. 
Table 1. Main demographic and clinical characteristics of 30 patients with Parkinson's disease included in the study and 194 patients with PD, seen in the outpatient's clinic for movement disorders over 2 years

\begin{tabular}{lccc}
\hline & $\begin{array}{l}\text { Patients with assessment of } \\
\text { sleep and sleepiness }(\mathrm{n}=30)\end{array}$ & $\begin{array}{l}\text { Outpatients } \\
(\mathrm{n}=194)\end{array}$ & $\mathrm{p}$ \\
\hline Age, years & $65 \pm 10(45-78)$ & $67 \pm 10(36-89)$ & $\mathrm{NS}$ \\
Disease duration, years & $8.2 \pm 6.6(0-29)$ & $8.5 \pm 6.6(0-29)$ & $\mathrm{NS}$ \\
UPDRS III & $25 \pm 10(7-44)$ & $24 \pm 12(4-74)$ & $\mathrm{NS}$ \\
Hoehn and Yahr Stage & $2.5 \pm 0.9(1-4)$ & $2.5 \pm 1(1-4)$ & $\mathrm{NS}$ \\
Dopamine agonist equivalent dose, mg & $205 \pm 230(0-700)$ & $211 \pm 218(0-1,000)$ & $\mathrm{NS}$ \\
Levodopa equivalent dose, mg & $651 \pm 531(0-2,011)$ & $632 \pm 436(0-2,140)$ & NS \\
\hline
\end{tabular}

Values are means \pm SD (range). UPDRS III = Unified Parkinson's Disease Rating Scale part III.

Subjective (as assessed by ESS) and objective (as assessed by MSLT) EDS in PD was systematically examined in 8 studies. In 6 studies, consecutive unselected PD patients were included $[3,4,9,10,12,13]$. In 2 studies, only PD patients referred for sleepiness or with ESS $>10$ were examined [5, 6]. Various factors including age [14, 15], gender $[1,16]$, dopaminergic treatment $[9,17,18]$, severity of PD $[18,19]$ and night-time sleep disturbances $[5,12]$ have been discussed as causes of EDS in PD. Neurons producing hypocretin (a hypothalamic protein involved in sleep-wake regulation, food intake and reward mechanism) were recently shown to be reduced in PD [20,21]. Low cerebrospinal fluid (CSF) hypocretin-1 levels were found in 1 study assessing severe idiopathic PD patients [22], but were not confirmed in 3 subsequent studies [11, $23,24]$.

The aim of this study was to assess, by means of a multimodal approach, the characteristics and potential determinants of EDS in a nonselected population of $\mathrm{PD}$ patients.

\section{Patients and Methods}

Daytime sleepiness and night-time sleep was assessed in 30 unselected consecutive patients ( 24 men; mean age $65 \pm 10$ years SD) with idiopathic PD, diagnosed according to the UK PD Brain Bank criteria [25]. The study was approved by the local ethics committee and all patients gave informed written consent prior to the study. Based on their characteristics, these patients were similar to $194 \mathrm{PD}$ patients seen in our outpatient clinic for movement disorders over a 2-year period (2005-2006; table 1).

The mean disease duration at the time of the polysomnography/MSLT was 8.2 years (SD 6.6 years), ranging from 1 month to 29 years. The mean Unified Parkinson's Disease Rating Scale part III (UPDRS III, motor score) was 25 (SD 10, range 7-44) in 'on' condition and the mean Hoehn and Yahr (HY) stage was 2.5 (SD
0.9 , range $1-4)$. Fourteen patients had advanced $\mathrm{PD}(\mathrm{HY} \geq 3)$, of whom 4 patients suffered from severe PD $(\mathrm{HY}=4)$. Sixteen of the 30 patients reported a depressed mood, 16 patients had memory difficulties, 11 had wearing-off symptoms, 8 had peak-dose dyskinesia and 8 experienced visual hallucinations. Antiparkinsonian drugs included levodopa $(n=22)$, non-ergot (pramipexole and ropinirole) and ergot (pergolide, cabergoline) derivatives $(\mathrm{n}=16)$, apomorphine $(\mathrm{n}=1)$, COMT inhibitors $(\mathrm{n}=5)$, amantadine $(\mathrm{n}=5)$, and anticholinergics $(\mathrm{n}=3)$. The mean levodopa equivalent dose was $651 \mathrm{mg}$ (SD 531, range 0-2,011). Six patients were taking sleeping pills and 10 patients were taking antidepressants.

Subjective sleepiness was assessed using ESS. All patients underwent standard nocturnal video-polysomnography consisting of 4 channel EEGs (C3/A2, C4/A1, O1/A2, O2/A1), left and right electro-oculography, submental electromyography, electrocardiography, respiratory flow (using a nasal cannula) and effort (using Medcare XactTrace respiratory inductive plethysmography technology belts), pulse oximetry, and left and right anterior tibialis electromyography. All recordings were done on Medcare Somnologica Studio. Sleep stages, periodic limb movements and arousals were scored manually according to international criteria [26-28]. Apnea and hypopnea were scored according to the recommendations of the American Academy of Sleep Medicine [29], but differing in that a desaturation of $4 \%$ instead of $3 \%$ was needed when the amplitude decrease did not reach $50 \%$. Sleep onset was defined as the first epoch of either NREM 2 or REM sleep.

On the day following the nocturnal recording, standard MSLT [30] was performed, starting 2 hours after waking up. For each patient, $4(n=20)$ or $5(n=5)$ naps, each with a duration of $20 \mathrm{~min}$ in 2-hour intervals were recorded. Sleep onset was defined as the first epoch of any sleep stage, including stage 1 . The naps were terminated after $20 \mathrm{~min}$. After each nap, the patients were asked to estimate if they had fallen asleep or not.

The hypocretin level in CSF was measured in 3 patients.

Statistical analysis was performed using SPSS 15 software. $\chi^{2}$ tests, t tests, repeated measures ANOVA and Mann-Whitney tests were used to analyze categorical and continuous variables. Pearson's correlation was used to measure the degree of association between MSL, ESS, subjectively reported sleep duration, nighttime sleep parameters, levodopa equivalent dose, disease severity and duration. The significance level was set at $\mathrm{p}<0.05$. 


\section{Results}

The data on ESS, polysomnography and MSLT of the entire population are presented in table 2 .

Sleep-disordered breathing [apnea/hypopnea index (AHI) $>10 / \mathrm{h}$ ] was found in 10 patients (33\% of the entire population), and was severe (AHI $>30$ ) in 5 of them. In 2 of these patients, CPAP treatment was previously attempted but not tolerated. In 3 patients, the apneas were mostly of central origin.

Periodic limb movements in sleep $(>10 / \mathrm{h})$ was found in 5 ( $17 \%$ of the entire population).

\section{Subjective Sleepiness (ESS)}

Seventeen patients (57\% of the entire population) reported subjective EDS (ESS $>10)$. In 7 patients (23\%), EDS was severe and 'narcolepsy like' (ESS $\geq 14$ ) [31].

Patients with EDS had a significantly higher dopamine agonist dose, higher levodopa equivalent dose, shorter night-time sleep latency and shorter MSL on MSLT than patients without EDS (table 3). Additionally, a trend towards a lower nocturnal percentage of REM sleep was observed. No significant differences were observed regarding age, gender, disease duration and severity (as expressed by UPDRS III and HY stage), or other polysomnographic sleep parameters. ESS did not correlate with the subjectively reported sleep duration at home.

\section{Objective Sleepiness (MSL on MSLT)}

The MSL on MSLT was 9.2 min (SD 6.4, range 0.3-20). Eleven patients (37\%) had severe objective EDS, which is a MSL $\leq 5 \mathrm{~min}$. In 53 of 125 nap opportunities (42\%), the sleep latency was $\leq 5 \mathrm{~min}$. Sixteen patients had at least 1 nap with a sleep latency $\leq 5 \mathrm{~min}$. From the 11 patients with a MSL $\leq 5 \mathrm{~min}$, in 7 patients, all naps had a sleep latency $\leq 5 \mathrm{~min}$ ( 4 of 4 naps in 6 patients, and 5 of 5 naps in 1 patient); in 3 patients, 3 out of 4 naps were with a sleep latency $\leq 5 \mathrm{~min}$; and in 1 patient, 2 out of 4 naps were with a sleep latency of $\leq 5 \mathrm{~min}$. Repeated measures ANOVA showed no significant difference between the mean duration of the naps, regardless of the time of the test (data sphericity was not violated, $\mathrm{p}=0.75, \mathrm{~F}_{3}=0.406$ ). The distribution of naps with sleep latency $\leq 5 \mathrm{~min}$ was as follows: $15 / 30$ in the 1 st nap, $10 / 30$ in the 2 nd nap, and 13/30 in both the $3 \mathrm{rd}$ and 4 th nap. These frequencies were not significantly different (Pearson $\chi^{2}, p=0.63$ ). There were 5 patients with a 5 th nap (in one of them sleep latency was $\leq 5 \mathrm{~min}$ ) and the mean duration of the 5th nap did not differ from the first 4 naps (table 4 ).

Excessive Daytime Sleepiness in

Parkinson's Disease
Table 2. ESS, polysomnographic and MSLT data in 30 consecutive patients with PD

\begin{tabular}{lcc}
\hline & Mean \pm SD & Range \\
\hline ESS score & $10 \pm 5$ & $0-17$ \\
Subjective night-time sleep duration, h & $6.5 \pm 1.9$ & $2-10$ \\
Total sleep time, min & $314 \pm 66$ & $165-421$ \\
Nocturnal sleep latency in PSG, min & $35 \pm 46$ & $2-227$ \\
Sleep efficiency, \% & $79 \pm 16$ & $28-98$ \\
REM latency, min & $118 \pm 87$ & $26-378$ \\
NREM 1, \% & $12 \pm 5$ & $1-24$ \\
NREM 2, \% & $43.4 \pm 14$ & $12-81$ \\
Slow wave sleep, \% & $12 \pm 9$ & $0.1-33$ \\
REM, \% & $12 \pm 7$ & $0-27$ \\
AHI & $15 \pm 21$ & $0-63$ \\
PLMS index & $10 \pm 22$ & $0-81$ \\
Mean sleep latency in MSLT, min & $9.2 \pm 6.4$ & $0.3-20$ \\
\hline
\end{tabular}

PSG = Polysomnography; AHI = apnea/hypopnea index; PLMS = periodic leg movement in sleep.

Table 3. PD patients with (ESS $>10)$ and without subjective EDS

\begin{tabular}{|c|c|c|c|}
\hline & $\begin{array}{l}\text { ESS }>10 \\
(n=17)\end{array}$ & $\begin{array}{l}\mathrm{ESS} \leq 10 \\
(\mathrm{n}=13)\end{array}$ & $\mathrm{p}$ \\
\hline Nocturnal sleep latency, min & $19 \pm 28$ & $57 \pm 56$ & 0.021 \\
\hline REM, \% & $10 \pm 6$ & $14 \pm 7$ & 0.087 \\
\hline $\begin{array}{l}\text { Mean sleep latency in MSLT, min } \\
\text { Dopamine agonist equivalent }\end{array}$ & $6 \pm 5$ & $13 \pm 6$ & 0.005 \\
\hline dose, $\mathrm{mg}$ & $310 \pm 226$ & $68 \pm 155$ & 0.003 \\
\hline Levodopa equivalent dose, mg & $836 \pm 426$ & $408 \pm 573$ & 0.026 \\
\hline
\end{tabular}

Only statistically significant results and trends are shown.

Table 4. Mean duration of the naps and number of naps with a sleep latency $\leq 5$ min depending on the time of the test

\begin{tabular}{llll}
\hline Nap No. & Patients, $n$ & Mean \pm SD & $\begin{array}{l}\text { Naps with a } \\
\text { SL } \leq 5 \text { min, } n\end{array}$ \\
\hline Nap 1 & 30 & $9.1 \pm 7.5$ & 15 \\
Nap 2 & 30 & $9.6 \pm 7.2$ & 10 \\
Nap 3 & 30 & $8.5 \pm 7.1$ & 13 \\
Nap 4 & 30 & $8.9 \pm 7.2$ & 13 \\
Nap 5 & 5 & $8.1 \pm 6.4$ & 1 \\
\hline
\end{tabular}

Repeated measures ANOVA $\mathrm{p}=0.75, \mathrm{~F}_{3}=0.406 ; \chi^{2} \mathrm{p}=0.63$. $\mathrm{SL}=$ Sleep latency. Because of the small number of patients with a 5 th nap these data were not included in the repeated measures ANOVA analysis and the $\chi^{2}$ statistics. 


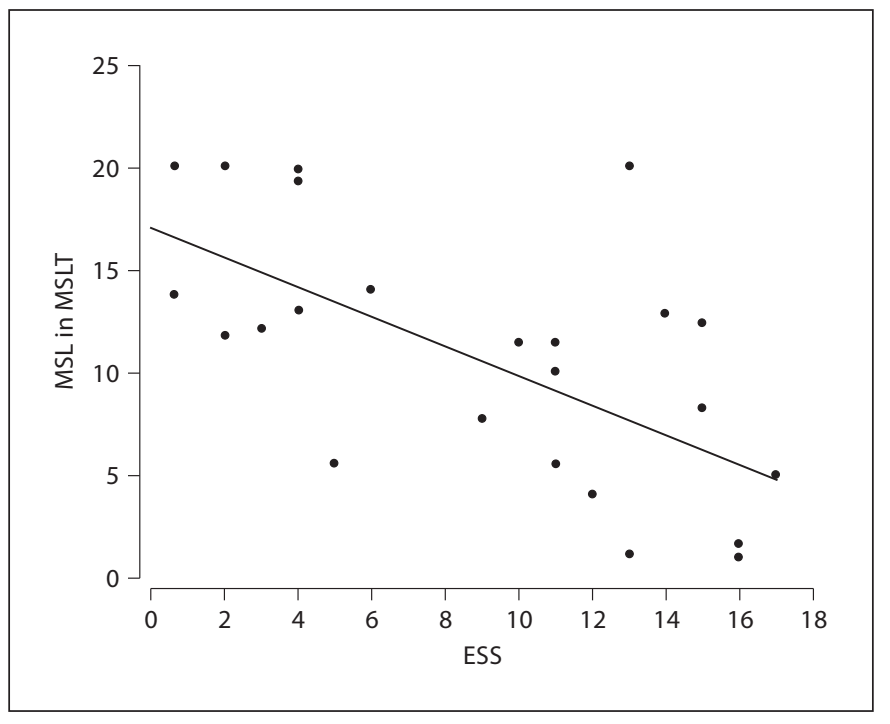

Fig. 1. Correlation between ESS and MSL in MSLT $(r=-0.65, p<$ 0.001).

Table 5. PD patients with (MSL $\leq 5 \mathrm{~min}$ ) and without severe objective EDS

\begin{tabular}{|c|c|c|c|}
\hline & $\begin{array}{l}\text { MSL } \leq 5 \\
(\mathrm{n}=11)\end{array}$ & $\begin{array}{l}\text { MSL >5 } \\
(\mathrm{n}=19)\end{array}$ & $\mathrm{p}$ \\
\hline ESS score & $14 \pm 2$ & $8 \pm 5$ & 0.001 \\
\hline Nocturnal sleep latency in PSG, min & $11 \pm 9$ & $50 \pm 53$ & 0.001 \\
\hline AHI & $24 \pm 26$ & $9 \pm 15$ & 0.026 \\
\hline $\begin{array}{l}\text { Dopamine agonist equivalent dose } \\
\mathrm{mg}\end{array}$ & $306 \pm 216$ & $146 \pm 222$ & 0.066 \\
\hline
\end{tabular}

Only significant results and trends are shown.

MSL = Mean sleep latency on MSLT; PSG = polysomnography.

A significant correlation between the subjectively reported sleep duration at home and MSL was observed only in the patients with ESS $>10(\mathrm{r}=0.531, \mathrm{p}=0.034)$.

A highly significant negative correlation was found between ESS and the MSL in MSLT $(r=-0.65, \mathrm{p}<0.001$; fig. 1).

Patients with MSL $<5$ min had significantly shorter nocturnal sleep latency, higher ESS scores and a higher AHI when compared to patients with MSL $>5$ min (table 5). A trend towards a higher dopamine agonist equivalent dose was also observed. No significant differences were observed regarding age, gender, disease duration and severity (as expressed by UPDRS III and HY stage), other polysomnographic sleep parameters, or overall levodopa equivalent dose.

In 15 patients (50\%), a sleep-wake misperception was present: 10 patients (33\%) did not realize they fell asleep (sleep-state misperception) in at least $1 \mathrm{nap}$, and the other 5 (17\%) thought they fell asleep although they did not (wake-state misperception). Patients with sleep-state misperception did not differ from the rest of the population studied regarding ESS, MSL, night-time parameters, demographic characteristics, disease duration or severity. Patients with wake-state misperception had significantly longer MSL $(17.2 \pm 3.8 \mathrm{~min})$ in comparison to the rest of the population $(7.5 \pm 5.6 \mathrm{~min}, \mathrm{p}<0.001)$. Five patients with ESS $>10$ had normal MSL in MSLT ( $>8 \mathrm{~min}$ ) and only 1 patient with short MSL (5.6 min) had a normal ESS (5/24 points).

No correlation was observed between ESS or MSL and age.

SOREM was not recorded in any test in any of the 11 patients with MSL $\leq 5 \mathrm{~min}$ who slept for $15 \mathrm{~min}$ after sleep onset. As the naps were terminated after $20 \mathrm{~min}$, SOREM in the rest of the patients is not reported.

No significant differences regarding ESS, MSL and night-time parameters were observed between patients with advanced/severe $(\mathrm{HY} \geq 3, \mathrm{n}=14)$ and beginning/ light $(\mathrm{HY}<3, \mathrm{n}=16) \mathrm{PD}$.

Eight patients reported hallucinations. Patients with hallucinations had significantly higher UPDRS III scores (33 \pm 9 vs. $21 \pm 9, \mathrm{p}=0.004)$, especially when tremor-related points were excluded ( $33 \pm 9$ vs. $19 \pm$ $10, \mathrm{p}=0.002)$, had a higher HY stage ( $3.1 \pm 0.8$ vs. 2.3 $\pm 0.9, \mathrm{p}=0.033)$ and less REM sleep $(6.2 \pm 7.5$ vs. 13.7 $\pm 5.6 \%, p=0.006)$. They tended to be objectively sleepier during the day than the patients without hallucinations (MSL in patients with hallucinations $5.8 \pm 5.9$ min, without hallucinations $10.4 \pm 6.3 \mathrm{~min}$, mean \pm $\mathrm{SD}, \mathrm{p}=0.081$ ) and fall asleep faster at night (night-time sleep latency in patients with hallucinations $13.9 \pm 11.1$ min, without hallucinations $43.3 \pm 51.5 \mathrm{~min}$, mean \pm $\mathrm{SD}, \mathrm{p}=0.07)$.

Patients with wearing-off symptoms $(\mathrm{n}=11)$ had lower MSL (5.9 \pm 5.8 vs. $11 \pm 6.1, \mathrm{p}<0.031)$, a higher HY stage ( $2.9 \pm 0.9$ vs. $2.2 \pm 0.9, \mathrm{p}=0.047)$, longer therapy duration $(9.9 \pm 5.2$ vs. $4.7 \pm 6.9$ years, $\mathrm{p}=0.04)$, a higher dopamine agonist equivalent dose (330 \pm 256 vs. 132 $\pm 183 \mathrm{mg}, \mathrm{p}=0.02)$ and a higher levodopa equivalent dose $(1,034 \pm 457$ vs. $429 \pm 445 \mathrm{mg}, \mathrm{p}=0.001)$ when compared to patients without wearing-off symptoms.

Both ESS and MSL correlated significantly with nocturnal sleep latency, dopamine agonist equivalent dose 
Table 6. Significant associations with subjective (ESS) or objective [mean sleep latency (MSL) in MSLT] measures of EDS

\begin{tabular}{|c|c|c|c|c|}
\hline & \multicolumn{2}{|l|}{ ESS } & \multicolumn{2}{|l|}{ MSL } \\
\hline & $\mathrm{r}$ & $\mathrm{p}$ & $\mathrm{r}$ & $\mathrm{p}$ \\
\hline Hoehn and Yahr stage & 0.074 & 0.698 & -0.063 & 0.741 \\
\hline UPDRS III & -0.082 & 0.673 & 0.091 & 0.640 \\
\hline Total sleep time & 0.067 & 0.725 & -0.150 & 0.427 \\
\hline Sleep efficiency in PSG & -0.205 & 0.277 & 0.052 & 0.785 \\
\hline Sleep latency, $\min$ & -0.599 & $<0.001$ & 0.581 & 0.001 \\
\hline REM, \% & -0.345 & 0.062 & 0.393 & 0.032 \\
\hline AHI & 0.392 & 0.032 & -0.347 & 0.042 \\
\hline \multicolumn{5}{|l|}{ Dopamine agonist equivalent } \\
\hline dose, $\mathrm{mg}$ & 0.562 & 0.001 & -0.484 & 0.007 \\
\hline Levodopa equivalent dose, mg & 0.392 & 0.032 & -0.348 & 0.059 \\
\hline
\end{tabular}

and AHI. ESS also correlated with levodopa equivalent dose and MSL to the percentage of REM sleep. No correlation was found with other nocturnal sleep parameters or disturbances, motor functioning (as expressed by UPDRS III in 'on' condition), disease duration or severity (as expressed by HY stage; table 6).

\section{CSF Hypocretin-1 Levels}

Hypocretin-1 level in CSF was measured in 3 patients and was in the normal range in all of them (low $<110 \mathrm{pg} /$ $\mathrm{ml}$, intermediate $110-200 \mathrm{pg} / \mathrm{ml}$, normal $>200 \mathrm{pg} / \mathrm{ml}$ ) [32].

The 1st patient denied having hallucinations, his ESS was 11, his MSL was $5.5 \mathrm{~min}$ and CSF hypocretin-1 levels were $454 \mathrm{pg} / \mathrm{ml}$. The 2 nd patient was a woman who repeatedly complained of EDS (ESS 13), but no sleep was registered in MSLT. She did not report hallucinations and her hypocretin level was normal at $519 \mathrm{pg} / \mathrm{ml}$. The other patient also complained of EDS (ESS 12), had MSL of $5 \mathrm{~min}$, and no SOREM was registered. He did not report hallucinations and his hypocretin in CSF was $260 \mathrm{pg} /$ $\mathrm{ml}$.

\section{Discussion}

Subjective and objective EDS are common in PD. Its main determinants include motor complications such as wearing-off symptoms, the dosage of antiparkinsonian drugs and sleep-disordered breathing. Severe, 'narcolepsy-like' EDS can be observed in PD even in the absence of SOREM and a detectable CSF hypocretin-1 deficit.
However, PD patients tended to overestimate their sleepiness, as there were more patients $(\mathrm{n}=5)$ with subjective sleepiness (ESS $>10$ ) and normal results in the objective test (normal MSL in MSLT), and only 1 patient with objective sleepiness (shortened MSL $<5 \mathrm{~min}$ ) and a normal ESS score.

\section{Frequency and Characteristics of EDS in $P D$}

Subjective (ESS $>10$ in 57\%) and objective EDS (MSL in MSLT $<5$ min in 37\%) were common in this PD population. Similar percentages were reported in previous studies $[1,3,4]$, including those with unselected PD patients. As already reported in the literature [33, 34], we did not find an association between EDS and age. Several studies have suggested a higher frequency of EDS in male $\mathrm{PD}$ patients $[1,16]$. In our sample, however, no gender differences were found.

An association between EDS and SOREM has been reported. Healthy subjects with multiple SOREMs were sleepier [35-37] than subjects with 1 or no SOREM. None of the 11 patients with MSL $\leq 5$ min presented with SOREM. Because naps were terminated after $20 \mathrm{~min}$ (instead of allowing the patients to sleep at least $15 \mathrm{~min}$ after sleep onset), we do not report on the occurrence of SOREM in the rest of the patients.

Sleep-misperception was observed in 10 patients (33\%), which is similar to previous reports in which sleep-state misperception in association with MSLT naps was reported in up to $38 \%$ of patients with PD and in $45 \%$ of patients with EDS [38]. In healthy subjects, sleep perception depends on sleep duration; after a 4-min nap, only $50 \%$ of healthy controls confirmed they had fallen asleep [39]. In a previous study, the patients with sleep misperception tended to underestimate their sleepiness in ESS [38]. No specific characteristics of PD with sleep misperception were found in our series.

There were also 5 patients who did not realize they fell asleep in at least 1 nap. These patients had longer mean sleep latencies on MSLT when compared to the rest of the study population. However, PD patients tended to overestimate their sleepiness, as there were more patients $(\mathrm{n}=5)$ with subjective sleepiness (ESS $>10)$ and normal results in the objective test (normal MSL in MSLT), and only 1 patient with objective sleepiness (shortened MSL $<5 \mathrm{~min}$ ) and a normal ESS score.

As already shown by others [10], ESS correlated significantly with MSL. This supports the use of ESS as a screening tool in clinical practice for EDS in PD patients. 


\section{Determinants of EDS in $P D$}

Levodopa equivalent dose, sleep-disordered breathing, wearing-off phenomena and REM sleep amount during polysomnography were linked to EDS in our study (see below).

\section{EDS and Neurodegeneration (PD Severity)}

The neurodegenerative process itself has been implicated in the pathophysiology of EDS in PD. Longer disease duration $[1,40]$ and association with UPDRS III [41] and the HY stage $[14,18,41]$ have been reported. In our series, patients with advanced/severe PD $(\mathrm{HY} \geq 3)$ did not differ from patients with light/beginning PD (HY $<3$ ). However, patients with motor fluctuations - a sign of advanced PD - had significantly lower mean sleep latencies on MSLT. This may be related to the involvement, usually later in the course of $\mathrm{PD}$, not only of the nigrostriatal dopaminergic system but also of extrastriatal dopaminergic and non-dopaminergic neurons in the lower brainstem and midbrain [42] involved in sleep-wake regulation $[43,44]$.

\section{EDS and Treatment}

We found a dose-dependent effect for both dopamine agonists and the overall levodopa equivalent dose on EDS, but not for levodopa alone. Others have similarly shown that dopamine agonists [45] and the total levodopa equivalent dose $[3,14]$ are associated with EDS. Additionally, patients on levodopa monotherapy had lower risk for sleep attacks than patients on dopamine agonist monotherapy or patients on a combination of levodopa and a dopamine agonist [16]. Patients with sleep episodes while driving had a higher levodopa equivalent dose than those without [46]. In 15 untreated patients with PD, ESS increased and MSL decreased significantly after initiation of levodopa treatment [9]. These findings suggest that both the use of dopamine agonists and the levodopa equivalent dose are associated with excessive daytime sleepiness.
EDS and Polysomnographic Findings

In our series, 3 polysomnographic parameters (sleep latency, AHI, sleep latency, REM-sleep amounts) were linked to EDS.

Sleep latencies (at night and during the day) are markers of sleep propensity. Patients with shorter sleep latency at night also had shorter MSL during the day (during MSLT) and higher ESS scores, as partially shown by others $[3,4]$.

Sleep-disordered breathing (AHI $\geq 10$ ) was found in one third of our patients. Compared to patients without sleep-disordered breathing, this group had lower mean sleep latencies on MSLT, but similar ESS. Sleep-related breathing disorders may, therefore, contribute to EDS in PD patients, very likely without representing its main cause in most cases $[5,12]$. In 2 of our patients, CPAP was attempted, but not tolerated.

EDS and CSF Hypocretin-1 Levels

CSF hypocretin-1 level was measured in 3 of our patients and was in the normal range, confirming that EDS in PD may be severe even in the absence of a detectable hypocretin deficiency $[11,23,24]$.

\section{Conclusion}

Subjective and objective EDS are common in PD patients. Wearing-off symptoms, dosage of antiparkinsonian drugs and sleep-disordered breathing (but not age, gender or disease duration) are linked with EDS in PD patients. Severe, 'narcolepsy-like' EDS can be observed in PD even in the absence of SOREM and a detectable CSF hypocretin-1 deficit.

\section{Acknowledgment}

We thank Esther Werth, PhD, for her help with the sleep-wake tests
References

Eur Neurol 2010;63:129-135
1 Ondo WG, Dat Vuong K, Khan H, Atassi F, Kwak C, Jankovic J: Daytime sleepiness and other sleep disorders in Parkinson's disease. Neurology 2001;57:1392-1396.

2 Frucht S, Rogers JD, Greene PE, Gordon MF, Fahn S: Falling asleep at the wheel: motor vehicle mishaps in persons taking pramipexole and ropinirole. Neurology 1999;52:19081910.

3 Razmy A, Lang AE, Shapiro CM: Predictors of impaired daytime sleep and wakefulness in patients with Parkinson disease treated with older (ergot) vs newer (nonergot) dopamine agonists. Arch Neurol 2004;61:97102.

4 Rye DB, Bliwise DL, Dihenia B, Gurecki P: FAST TRACK: daytime sleepiness in Parkinson's disease. J Sleep Res 2000;9:63-69.

5 Arnulf I, Konofal E, Merino-Andreu M, et al: Parkinson's disease and sleepiness: an integral part of PD. Neurology 2002;58:10191024. 
66 Roth T, Rye DB, Borchert LD, et al: Assessment of sleepiness and unintended sleep in Parkinson's disease patients taking dopamine agonists. Sleep Med 2003;4:275-280.

7 Arnulf I, Bejjani BP, Garma L, et al: Hallucinations, REM sleep, and Parkinson's disease: a medical hypothesis. Neurology 2000;55: 281-288.

-8 Rye DB, Johnston LH, Watts RL, Bliwise DL: Juvenile Parkinson's disease with REM sleep behaviour disorder, sleepiness, and daytime REM onset. Neurology 1999;53:1868-1870.

9 Kaynak D, Kiziltan G, Kaynak H, Benbir G, Uysal O: Sleep and sleepiness in patients with Parkinson's disease before and after dopaminergic treatment. Eur J Neurol 2005;12: 199-207.

$\checkmark 10$ Monaca C, Duhamel A, Jacquesson JM, et al: Vigilance troubles in Parkinson's disease: a subjective and objective polysomnographic study. Sleep Med 2006;7:448-453.

-11 Baumann C, Ferini-Strambi L, Waldvogel D, Werth E, Bassetti CL: Parkinsonism with excessive daytime sleepiness - a narcolepsylike disorder? J Neurol 2005;252:139-145.

12 Stevens S, Cormella CL, Stepanski EJ: Daytime sleepiness and alertness in patients with Parkinson disease. Sleep 2004;27:967-972.

13 Shpirer I, Miniovitz A, Klein C, et al: Excessive daytime sleepiness in patients with Parkinson's disease: a polysomnography study. Mov Disord 2006;21:1432-1438.

14 Pal S, Bhattacharya KF, Agapito C, Chaudhuri KR: A study of excessive daytime sleepiness and its clinical significance in three groups of Parkinson's disease patients taking pramipexole, cabergoline and levodopa mono and combination therapy. J Neural Transm 2001;108:71-77.

-15 Gjerstad MD, Alves G, Wentzel-Larsen T, Aarsland D, Larsen JP: Excessive daytime sleepiness in Parkinson disease: is it the drugs or the disease? Neurology 2006;67: 853-858.

16 Paus S, Brecht HM, Koster J, Seeger G, Klockgether T, Wullner U: Sleep attacks, daytime sleepiness, and dopamine agonists in Parkinson's disease. Mov Disord 2003;18:659667.

-17 Fabbrini G, Barbanti P, Aurilia C, Vanacore N, Pauletti C, Meco G: Excessive daytime sleepiness in de novo and treated Parkinson's disease. Mov Disord 2002;17:1026-1030.

-18 O’Suilleabhain PE, Dewey RB Jr: Contributions of dopaminergic drugs and disease severity to daytime sleepiness in Parkinson disease. Arch Neurol 2002;59:986-989.
-19 Diederich NJ, Vaillant M, Mancuso G, Lyen $\mathrm{P}$, Tiete J: Progressive sleep 'destructuring' in Parkinson's disease. A polysomnographic study in 46 patients. Sleep Med 2005;6:313318.

20 Thannickal TC, Lai YY, Siegel JM: Hypocretin (orexin) cell loss in Parkinson's disease. Brain 2007;130:1586-1595.

21 Fronczek R, Overeem S, Lee SY, et al: Hypocretin (orexin) loss in Parkinson's disease. Brain 2007; 130:1577-1585.

22 Drouot X, Moutereau S, Nguyen JP, et al: Low levels of ventricular CSF orexin/hypocretin in advanced PD. Neurology 2003;61:540543.

23 Overeem S, van Hilten JJ, Ripley B, Mignot E, Nishino S, Lammers GJ: Normal hypocretin-1 levels in Parkinson's disease patients with excessive daytime sleepiness. Neurology 2002;58:498-499.

24 Yasui K, Inoue Y, Kanbayashi T, Nomura T, Kusumi M, Nakashima K: CSF orexin levels of Parkinson's disease, dementia with Lewy bodies, progressive supranuclear palsy and corticobasal degeneration. J Neurol Sci 2006; 250:120-123.

25 Gibb WR, Lees AJ: The relevance of the Lewy body to the pathogenesis of idiopathic Parkinson's disease. J Neurol Neurosurg Psychiatry 1988;51:745-752.

26 Rechtschaffen A, Kales A: A Manual of Standardized Terminology, Techniques and Scoring System for Sleep Stages of Human Subjects. Los Angeles, UCLA Brain Information Service/Brain Research Institute, 1968.

27 EEG arousals: scoring rules and examples. A preliminary report from the Sleep Disorders Atlas Task Force of the American Sleep Disorders Association. Sleep 1992;15:174-184.

28 American Academy of Sleep Medicine: International Classification of Sleep Disorders: Diagnostic and Coding Manual, ed 2., Westchester, American Academy of Sleep Medicine, 2005.

29 Sleep-related breathing disorders in adults: recommendations for syndrome definition and measurement techniques in clinical research. The Report of an American Academy of Sleep Medicine Task Force. Sleep 1999;22: 667-689.

30 Carskadon MA, Dement WC, Mitler MM, Roth T, Westbrook PR, Keenan S: Guidelines for the multiple sleep latency test (MSLT): a standard measure of sleepiness. Sleep 1986 9:519-524.

-31 Sturzenegger C, Bassetti CL: The clinical spectrum of narcolepsy with cataplexy: a reappraisal. J Sleep Res 2004;13:395-406.

32 Mignot E, Lammers GJ, Ripley B, et al: The role of cerebrospinal fluid hypocretin measurement in the diagnosis of narcolepsy and other hypersomnias. Arch Neurol 2002;59: 1553-1562.
33 Arnulf I: Excessive daytime sleepiness in parkinsonism. Sleep Med Rev 2005;9:185200 .

34 Hobson DE, Lang AE, Martin WR, Razmy A, Rivest J, Fleming J: Excessive daytime sleepiness and sudden-onset sleep in Parkinson disease: a survey by the Canadian Movement Disorders Group. JAMA 2002;287: 455-463

35 Bishop C, Rosenthal L, Helmus T, Roehrs T, Roth T: The frequency of multiple sleep onset REM periods among subjects with no excessive daytime sleepiness. Sleep 1996;19:727730 .

>36 Singh M, Drake CL, Roth T: The prevalence of multiple sleep-onset REM periods in a population-based sample. Sleep 2006;29: 890-895

37 Mignot E, Lin L, Finn L, Lopes C, Pluff K, Sundstrom ML, Young T: Correlates of sleeponset REM periods during the Multiple Sleep Latency Test in community adults. Brain 2006;129:1609-1623.

-38 Merino-Andreu M, Arnulf I, Konofal E, Derenne JP, Agid Y: Unawareness of naps in Parkinson's disease and in disorders with excessive daytime sleepiness. Neurology 2003; 60:1553-1554.

39 Bonet M, Moore S: The threshold of sleep: perception of sleep as a function of time asleep and auditory threshold. Sleep 1982;5: 267-276.

40 Tan EK, Lum SY, Fook-Chong SM, et al: Evaluation of somnolence in Parkinson's disease: comparison with age- and sexmatched controls. Neurology 2002;58:465468 .

41 Kumar S, Bhatia M, Behari M: Excessive daytime sleepiness in Parkinson's disease as assessed by Epworth Sleepiness Scale (ESS). Sleep Med 2003;4:339-342.

-42 Braak H, Ghebremedhin E, Rub U, Bratzke H, Del Tredici K: Stages in the development of Parkinson's disease-related pathology. Cell Tissue Res 2004;318:121-134.

$\checkmark 43$ Saper CB, Scammell TE, Lu J: Hypothalamic regulation of sleep and circadian rhythms. Nature 2005;437:1257-1263.

44 Lu J, Sherman D, Devor M, Saper CB: A putative flip-flop switch for control of REM sleep. Nature 2006;441:589-594.

45 Hogl B, Seppi K, Brandauer E, et al: Increased daytime sleepiness in Parkinson's disease: a questionnaire survey. Mov Disord 2003;18: 319-323.

46 Brodsky MA, Godbold J, Roth T, Olanow CW: Sleepiness in Parkinson's disease: a controlled study. Mov Disord 2003;18:668-672. 